Estudios sobre armas antiguas, arte militar $\mathrm{y}$ vida cultural en oriente y occidente XXXIX (2019), pp. 71-91

ISSN: 0436-029X

https://doi.org/10.3989/gladius.2019.04

\title{
RECLUTAMIENTO Y UNIDADES MILITARES EN LAS COLONIAS ROMANAS DE LA HISPANIA CITERIOR*
}

\author{
RECRUITMENT AND MILITARY UNITS IN THE \\ ROMAN COLONIES OF HISPANIA CITERIOR
}

POR

José ORTIZ CóRDOBA**

\section{RESUMEN - ABstract}

La participación de tropas de origen hispano en el ejército romano fue frecuente a lo largo del Alto Imperio. Este trabajo tiene como objetivo el estudio de aquellos militares reclutados en las colonias romanas de la Hispania Citerior que fallecieron lejos de las mismas durante su periodo de servicio activo o bien tras recibir la honesta missio y decidir instalarse como veterani en su lugar de destino.

The participation of soldiers of Hispanic origin in the Roman army was frequent during the High Empire. This article analyses the mobility of those military men recruited in the colonies of Hispania Citerior who died far from them during their either service or after receiving the honesta missio and deciding to settle as veterans in their destination.

\section{Palabras Clave - Keywords}

Ejército romano; movilidad; colonización; colonias; Hispania Citerior; milites.

Roman army; mobility; colonization; colonies; Hispania Citerior; milites.

\section{Cómo CITAR eSte ARTículo / Citation}

Ortiz Córdoba, J. (2019): «Reclutamiento y unidades militares en las colonias romanas de la Hispania Citerior»». Gladius, XXXIX: 71-91. https://doi.org/10.3989/gladius.2019.04

\section{INTRODUCCIÓN}

La plena integración de la península ibérica en el mundo romano tuvo como principal consecuencia el aumento de la presencia de hispanos en diferentes áreas. Una de ellas fue

* Este trabajo se enmarca dentro de las líneas de estudio del grupo de investigación HUM-215 dirigido por el Prof. Dr. C. González Román y deriva de la tesis doctoral Las colonias romanas de Hispania y los movimientos de población (siglos I-II d. C.), defendida en la Universidad de Granada en marzo de 2019. Asimismo, forma parte del proyecto de investigación Veterani et milites en las colonias romanas de Hispania, otorgado a quien suscribe estas líneas por el Plan Propio de Investigación de la Universidad de Granada en el marco del Programa de Proyectos de Investigación para Jóvenes Investigadores.

** Ayuda puente doctores Plan Propio. Departamento de Historia Antigua, Universidad de Granada, joseortiz@ugr.es / ORCID iD: https://orcid.org/0000-0003-3737-1115 
el ejército, que constituyó durante la Antigüedad uno de los colectivos con mayor índice de movilidad. Esta puede detectarse a través de la epigrafía, donde numerosos milites hicieron constar con orgullo su origo (Perea Yébenes, 2004-2005). La presencia de hispanos en el ejército romano fue una constante durante el periodo altoimperial, aunque con anterioridad al mismo las fuentes literarias nos informan de la participación en diferentes conflictos de grupos compuestos por mercenarios de origen peninsular (García-Gelabert Pérez y Blázquez Martínez, 1987-1988). Quizás el ejemplo más claro de esta dinámica sea el de los integrantes de la llamada de la Turma Salluitana, jinetes procedentes de la zona del Ebro que tomaron parte en la Guerra Social y a quienes Cneo Pompeyo Estrabón concedió la ciudadanía romana, según consta en el bronce de Ascoli (CIL VI, 37045). Con posterioridad, ya durante el Principado, la participación en el ejército romano de militares de origen hispano fue bastante amplia. Su presencia ha sido documentada en diversos puntos de la geografía imperial, entre los que destaca particularmente el limes renano-danubiano ${ }^{1}$.

Una parte importante de esos contingentes militares hispanos fue reclutada en las colonias romanas de la península ibérica, ciudades mayormente de origen militar donde la continuidad del oficio castrense parece mantenerse durante un tiempo prolongado. El trabajo que ahora presentamos tiene como principal objetivo abordar el estudio de aquellos militares que fueron reclutados en algunas de estas colonias hispanas y que fallecieron lejos de las mismas durante su periodo de servicio activo o tras haber recibido la honesta missio y decidido instalarse como veterani en el que había sido hasta ese momento su lugar de destino. Para llevar a cabo este análisis emplearemos un concepto de movilidad que viene marcado por mostrar un carácter de migración, es decir, de permanencia en el lugar de destino, característica que lo diferencia de otro tipo de movimientos de población que implican un retorno al lugar de origen. El principal criterio empleado para detectar la existencia de esta movilidad está conformado por la indicación de la origo. Este término señala la comunidad cívica a la que está adscrita el individuo en cuestión, generalmente diferente a la del lugar de hallazgo de la inscripción. El empleo de esta fórmula revela el interés de la persona que lo usa por vincularse con su patria de origen, con la que es probable que siguiera manteniendo importantes lazos afectivos y, en algunos casos, también económicos y sociales (Sobre la origo véase: Andreu Pintado, 2008: 349-352; Grüll, 2018). En base a este criterio hemos elaborado un corpus compuesto por 23 inscripciones que aluden a 25 individuos y que conforma la base documental de esta contribución. Con ella completamos la serie de trabajos dedicados al estudio de los reclutamientos militares que tuvieron lugar en las colonias hispanas, en los que ya abordamos con anterioridad los casos de la Bética (Ortiz Córdoba, 2017) y de Lusitania (Ortiz Córdoba, 2018).

Las ciudades elegidas para llevar a cabo este trabajo, las diez colonias romanas existentes en la Hispania Citerior, constituyen algunos de los principales centros urbanos de la provincia. Esta fue creada en el año 197 a. C., aunque en ese momento Roma dominaba únicamente algunas zonas concretas de la costa levantina y del valle del Ebro. En consecuencia, su límite occidental fue incierto durante mucho tiempo y estuvo sometido a continuas modificaciones derivadas de la conquista del interior peninsular. Una vez completada la misma, la Citerior

\footnotetext{
1 La composición y el sistema de reclutamiento de las legiones romanas fue abordada por G. Forni (1953) en un trabajo que podemos considerar clásico. Con posterioridad, la participación de hispanos en el ejército romano fue estudiada en los trabajos de carácter general desarrollados por J. M. Roldán Hervás (1974) y P. Le Roux (1982). Existen igualmente numerosas contribuciones relativas a las provincias hispanas (para la Bética: Perea Yébenes, 1994; Morales Rodríguez, 2014; Ortiz Córdoba, 2017; para Lusitania: Gutiérrez Merino, 2002; Ortiz Córdoba, 2018; para la Citerior: Perea Yébenes, 2001). Algunos aspectos parciales sobre militares oriundos de la península se encuentran también en diversos trabajos sobre la emigración hispana (García Martínez, 1991; 1994a; 1994b; Ricci, 1992; 2005). De forma reciente los testimonios de militares hispanos documentados en el limes septentrional han sido reunidos por L. Hernández Guerra (2017).
} 
se configuró como la provincia más grande de Hispania. Este hecho condicionó su evolución histórica, dado que existieron importantes contrastes entre las tierras costeras y el valle del Ebro, donde la vida urbana era intensa y el desarrollo económico mayor, y las regiones del interior, que apenas contaban con vida urbana y cuyos recursos, si exceptuamos la riqueza minera del noroeste, eran más exiguos. La administración de esta extensa provincia contó con especificidades propias, dado que los conventus iuridici jugaron en ella un papel clave como elemento vertebrador de la administración romana (Ozcáriz Gil, 2013: 55-96; Dopico Caínzos, 2017), sobre todo en las tierras del interior, donde las estructuras gentilicias se mantuvieron con posterioridad a la conquista (González Rodríguez, 2017). Sobre esta enorme provincia la colonización romana tuvo un impacto relativo si lo comparamos con una región de menor tamaño como fue la Bética. La misma se concentró principalmente en su zona costera, donde encontramos algunos de los principales centros urbanos de la península ibérica. Nueve de esas colonias remiten al periodo cesariano y augusteo, como podemos ver en la tabla 1.

Tabla 1. Colonias fundadas por César y Augusto en la Hispania Citerior.

\begin{tabular}{|c|c|c|c|}
\hline Colonia & Localización & Fundación & Origen colonos \\
\hline Caesar Augusta & Zaragoza & $\begin{array}{l}\text { Fundada por Augusto. Se han propuesto las } \\
\text { fechas del } 25 \text { a.C. y, más probablemente, las del } \\
19 \text { a.C. o el bienio } 15-14 \text { a.C. }\end{array}$ & $\begin{array}{l}\text { Legs. IIII } \\
\text { Macedonica; } V I \\
\text { Victrix; } \text { X Gemina }\end{array}$ \\
\hline $\begin{array}{c}\text { Iulia Augusta } \\
\text { Paterna Faventia } \\
\text { Barcino } \\
\end{array}$ & Barcelona & $\begin{array}{l}\text { Fundación de Augusto durante su tercer viaje a } \\
\qquad \text { Hispania (15-13 a.C.) }\end{array}$ & \\
\hline $\begin{array}{l}\text { Iulia Gemella } \\
\text { Acci }\end{array}$ & $\begin{array}{l}\text { Guadix } \\
\text { (Granada) }\end{array}$ & $\begin{array}{l}\text { Fundación de época triunviral, posiblemente } \\
\text { entre los años } 31 \text { y } 27 \text { a.C. }\end{array}$ & Legs. I y II \\
\hline $\begin{array}{l}\text { Iulia Ilici } \\
\text { Augusta }\end{array}$ & $\begin{array}{l}\text { La Alcudia de } \\
\text { Elche (Alicante) }\end{array}$ & $\begin{array}{c}\text { Fundación de Lépido en el año } 42 \text { a.C. Segundo } \\
\text { asentamiento de colonos militares en época de } \\
\text { Augusto ( } 27-26 \text { a.C.) }\end{array}$ & $\begin{array}{c}\text { Colonos de origen } \\
\text { militar y habitantes } \\
\text { de la ciudad de } \\
\text { Icosium }\end{array}$ \\
\hline $\begin{array}{l}\text { Iulia Urbs } \\
\text { Triumphalis } \\
\text { Tarraco }\end{array}$ & Tarragona & $\begin{array}{l}\text { Fundación cesariana entre los años } 45 / 44 \text { y } 36 \\
\text { a.C. Llevada a cabo posiblemente por } P \text {. Mucius } \\
\text { Scaevola como praefectus del Dictador }\end{array}$ & Legs. Martia y VI \\
\hline $\begin{array}{l}\text { Libisosa Forum } \\
\text { Augustana }\end{array}$ & $\begin{array}{c}\text { Lezuza } \\
\text { (Albacete) }\end{array}$ & $\begin{array}{l}\text { Fundación de Augusto posterior al año } 27 \text { a.C. } \\
\text { Anteriormente se configuró como un Forum, } \\
\text { quizás por concesión de César }\end{array}$ & \\
\hline Salaria & $\begin{array}{l}\text { Úbeda la Vieja } \\
\qquad(\text { Jaén) }\end{array}$ & Probablemente augustea & \\
\hline $\begin{array}{l}\text { Urbs Iulia Nova } \\
\text { Carthago }\end{array}$ & $\begin{array}{l}\text { Cartagena } \\
\text { (Murcia) }\end{array}$ & $\begin{array}{l}\text { Fundación de época triunviral. Contó } \\
\text { probablemente con un segundo asentamiento de } \\
\text { población en época de Augusto }\end{array}$ & \\
\hline $\begin{array}{l}\text { Victrix Iulia } \\
\text { Lepida/Celsa }\end{array}$ & $\begin{array}{l}\text { Velilla del Ebro } \\
\text { (Zaragoza) }\end{array}$ & $\begin{array}{l}\text { Fundada por M. Emilio Lépido entre los años } \\
\text { 44-42 a.C. En el } 36 \text { a.C. cambió su nombre a } \\
\text { instancias de Augusto }\end{array}$ & \\
\hline
\end{tabular}

Todas estas fundaciones presentan características históricas y sociológicas que podríamos considerar similares, dado que fueron creadas en un periodo temporal más o menos concreto y 
en el marco de unas circunstancias históricas determinadas. Las mismas estuvieron marcadas por la resolución del proceso de crisis secular que conocemos con el nombre de Revolución Romana, cuyo desarrollo supuso la quiebra definitiva de las instituciones republicanas. Por tanto, una buena parte de estas colonias tuvo un origen militar, consecuencia directa de las deductiones de veteranos que fueron empleadas como uno de los instrumentos más eficaces para poner fin a este periodo revolucionario. A estas nueve colonias debemos añadir el caso de Clunia Sulpicia (Peñalba de Castro, Burgos), cuyo rango colonial conocemos a través de la documentación literaria (Ptolomeo, Geographia, II, 6, 55) y epigráfica (CIL II, 2780). Su concesión ha sido vinculada tradicionalmente con Galba (Haley, 1992, bibliografía al respecto en nota 1), aunque la misma ha suscitado diversas consideraciones en la historiografía (Castillo, 1988: 234; Faria, 1999: 32), habiéndose propuesto incluso el adelanto de la promoción colonial hasta época de Claudio o Nerón (Perea Yébenes, 2001: 219).

Desde un punto de vista cronológico nuestro trabajo se ciñe a los siglos I y II d. C., periodo que abarca la etapa histórica que usualmente conocemos como Alto Imperio o Principado. Este marco temporal coincide también en buena medida con el desarrollo del proceso de colonización romana (una revisión del mismo para el caso hispano la podemos encontrar en Ortiz Córdoba, 2019: 97-531). La delimitación cronológica escogida debe relacionarse igualmente con la propia evolución histórica del mundo romano, donde los cambios protagonizados por la dinastía Severa inauguraron una etapa marcada por los nuevos parámetros sociales derivados de la unificación jurídica que trajo consigo la Constitutio Antoniniana. Entre ellos se encuentra la simplificación del sistema onomástico romano, donde la mención de la origo fue decayendo progresivamente, hecho que dificulta y limita nuestro conocimiento sobre las dinámicas de movilidad existentes durante la Antigüedad tardía.

\section{LOS MILITARES DESPLAZADOS}

La documentación epigráfica que hemos reunido para elaborar este trabajo está compuesta por 23 inscripciones que hacen referencia a 25 individuos. La distribución de los mismos en función de sus lugares de origen aparece recogida en la figura 1, donde podemos observar que la mayoría de los milites estudiados procedía de Caesar Augusta y Clunia.

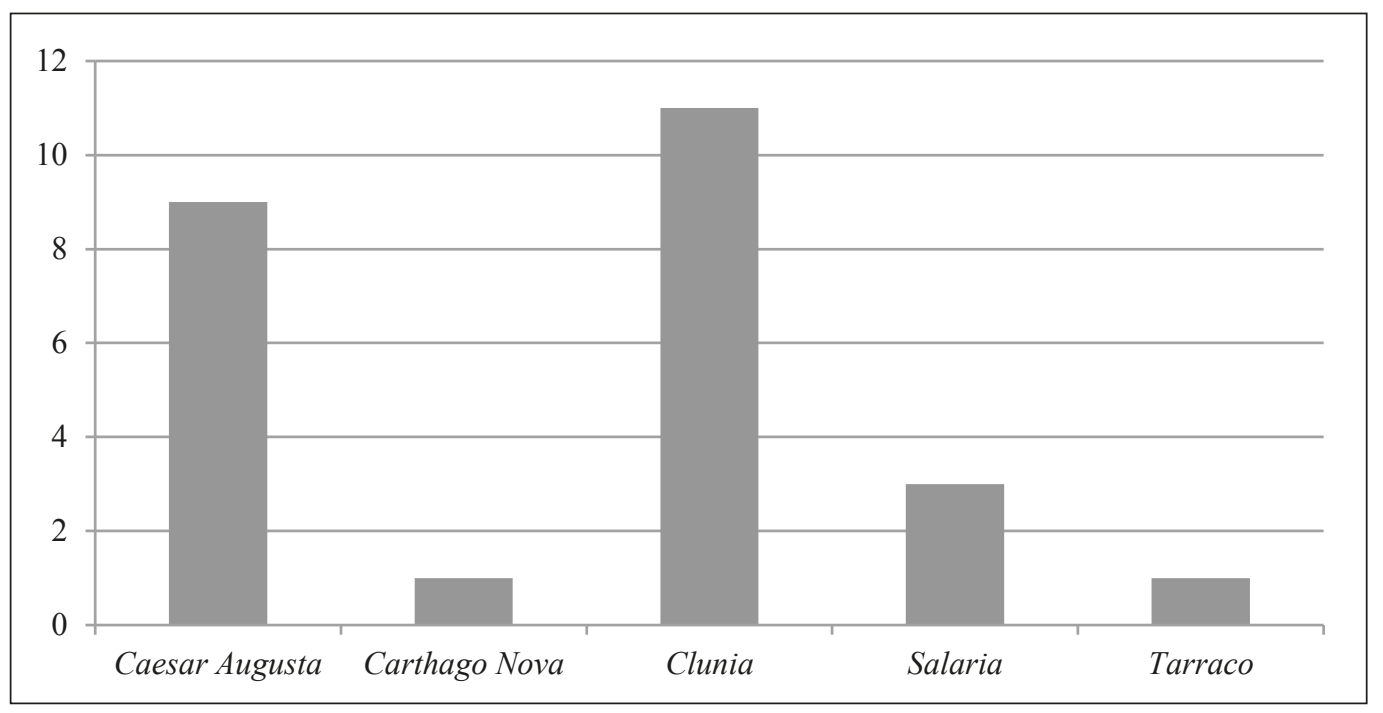

Figura 1. Colonias de procedencia de los milites estudiados. 


\subsection{UNIDADES DOCUMENTADAS}

A la hora de identificar las unidades en las que prestaron servicio los militares reclutados en las colonias hispanas de la Citerior contamos con una importante variedad. Hemos detectado un total de doce legiones diferentes, a las que debemos sumar tres cuerpos auxiliares y también el caso de los hispanos que fueron enrolados en las cohortes pretorianas de Roma. Las unidades documentadas y el número de componentes que pertenecieron a cada una de ellas aparecen detalladas en la tabla 2.

Tabla 2. Unidades militares constatadas y distribución de la documentación.

\begin{tabular}{|c|c|}
\hline Nombre de la unidad & $\begin{array}{c}\text { Número } \\
\text { de testimonios }\end{array}$ \\
\hline \multicolumn{2}{|c|}{ Legiones } \\
\hline Legio VII Gemina & 3 \\
\hline Legio XIIII Gemina & 3 \\
\hline Legio XX Valeria Victrix & 2 \\
\hline Legio X Gemina & 1 \\
\hline Legio IIII Macedonica & 1 \\
\hline Legio III Augusta & 1 \\
\hline Legio I Adiutrix & 1 \\
\hline Legio II Adiutrix & 1 \\
\hline Legio I Italica & $\begin{array}{c}1 * \\
\text { (sirvió también en la } \\
\text { Cohors V Asturum) }\end{array}$ \\
\hline Legio IIII Flavia & 1 \\
\hline Legio XI Claudia & 1 \\
\hline Legio VIIII Hispana & 1 \\
\hline \multicolumn{2}{|c|}{ Unidades auxiliares } \\
\hline Ala I Hispanorum & 1 \\
\hline Ala III Thracum & 1 \\
\hline Cohors V Asturum & $\begin{array}{c}1 * \\
\text { (sirvió también en la } \\
\text { Legio I Italica) }\end{array}$ \\
\hline \multicolumn{2}{|c|}{ Cohortes pretorianas } \\
\hline & 3 \\
\hline \multicolumn{2}{|c|}{ Legionarios sin unidad determinada } \\
\hline 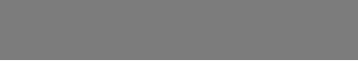 & 3 \\
\hline
\end{tabular}




\section{2. ÁREAS DE DESTINO}

Para llevar a cabo el estudio de la documentación epigráfica reunida en este trabajo hemos creado dos grandes áreas geográficas correspondientes a la península ibérica, donde contamos con cinco referencias, y a las provincias del resto del Imperio, de donde proceden los veinte casos restantes (Fig. 2).

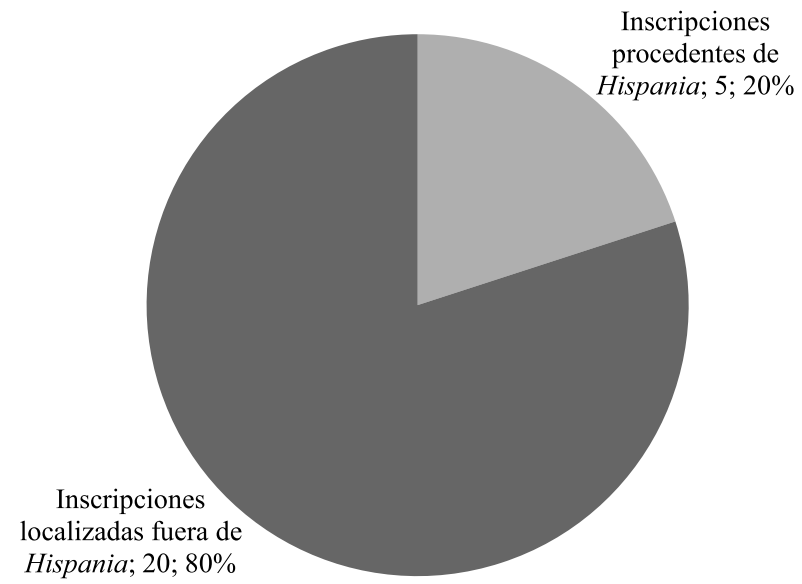

Figura 2. Distribución geográfica de los testimonios epigráficos estudiados.

\subsubsection{Hispania}

De la península ibérica proceden cinco de las inscripciones estudiadas en este trabajo. En ellas han sido documentados otros tantos legionarios originarios de Caesar Augusta (4) y Clunia (1).

El grupo más numeroso dentro de este apartado está compuesto por los cuatro veteranos de origen caesaraugustano. Sus inscripciones, salvo en un caso, remiten al siglo I d. C. Esta temprana fecha, junto al servicio de algunos de ellos en las legiones X Gemina y IIII Macedonica, ambas participantes en la deductio de la colonia, nos ha permitido plantear la posibilidad de que se tratase de descendientes de los primeros colonos caesaraugustanos (Ortiz Córdoba, 2019: 386-388). Este sería el caso de los veterani [---] Tertius (n. $\left.{ }^{\circ} 5\right)^{2}$ y Marcus Valerius Secundus. Del primero de ellos, cuya inscripción procede de Vareia, (Varea, La Rioja), conocemos únicamente su cognomen, aunque su origo y su pertenencia a la tribu Aniensis no dejan lugar a dudas sobre su vinculación con Caesar Augusta. Este personaje sirvió en la legio IIII Macedonica, estando ya retirado en el momento de su fallecimiento en Vareia, como indican su designación como veteranus y su avanzada edad, setenta años. Su epitafio fue dedicado por su heredero en cumplimiento de un mandato testamentario. La inscripción podría datarse entre los reinados de Tiberio y Nerón, más concretamente en una horquilla temporal que abarcaría los años 30-35 d. C. y 65-70 d. C. Se trata de una fecha flexible dado que, entre otras cosas, la edad de [---] Tertius aparece redondeada por lo menos en lustros (Espinosa Ruiz, 1990: 11; Espinosa Ruiz y Castillo Pascual, 1995-1997: 104). En cualquier caso, su carácter de veteranus

2 AE 1997, 912: [---] / f(ilius) $\cdot$ Tertius $\cdot v[$ [et(eranus)] / leg(ionis) $\cdot$ IIII $\cdot$ Mac[ed(onicae)] / Anie $($ n)sis $\cdot$ Caes[ara]/ ugustanus $\cdot a[n n] /$ orum $\cdot L X X \cdot h($ ic $)[s($ itus $) e($ st $)] / h($ eres $) \cdot$ ex $\cdot$ t(estamento) 
permite considerar que este legionario habría sido relevado del servicio antes del traslado de la IIII Macedonica al limes germano, acontecimiento que tuvo lugar entre los años 39-43 d. C. Tras recibir la honesta missio decidió asentarse en la misma zona en la que había servido en lugar de retornar a su ciudad natal.

La segunda de las inscripciones que recogemos en este apartado procede de Petavonium (Rosino de Vidriales, Zamora) y conforma el epitafio de Marcus Valerius Secundus (n. $\left.{ }^{\circ} 3\right)^{3}$. Se trata de una inscripción breve donde apenas se detalla información sobre este personaje, del que únicamente conocemos su estatus de veteranus y su pertenencia a la tribu Aniensis, lo que nos permite relacionarlo con Caesar Augusta, única ciudad hispana cuyos habitantes fueron inscritos en esta tribu (Wiegels, 1985: 101). Tampoco aparece consignada su unidad de servicio, aunque el hallazgo de su inscripción en Petavonium, sede de la X Gemina en Hispania, permite suponer que se trataría de un veteranus de esta unidad. Su reclutamiento habría tenido lugar en época de Tiberio o Claudio, por lo que P. Le Roux (1982: 182, n. 40 y 326) situó su inscripción entre mediados y finales del siglo I d. C., aunque para L. Hernández Guerra (1999: 38) esta fecha podría adelantarse hasta un periodo comprendido entre los años 37 y $43 \mathrm{~d}$. C.

Finalmente, consideramos que también pudo haber estado vinculado con la deductio de Caesar Augusta el veteranus Lucius Vissellius Niger $\left(\mathrm{n}^{\circ}{ }^{\circ} 4\right)^{4}$, que falleció en el territorio de Clunia entre la segunda mitad del siglo I y comienzos del siglo II d. C. Su inscripción no señala ni la unidad de servicio ni la ciudad de nacimiento de este legionario. Sin embargo, la presencia en la misma de la tribu Aniensis debe considerarse como un indicio claro de su relación con Caesar Augusta. La posible vinculación de L. Vissellius Niger con la fundación de esta colonia podría realizarse a través de su onomástica, que, en nuestra opinión, permitiría considerarlo como descendiente de uno de los primeros colonos itálicos (Ortiz Córdoba, 2019: 388). Inicialmente, la misma fue reconstruida como Asellius, lectura posteriormente corregida por J. A. Abásolo, que se inclinó por restituir el nomen de este personaje como Vissellius (Abásolo, 1994: 202), gentilicio documentado en Hispania únicamente en dos ocasiones (Abascal, 1994: 249). Según este autor estaríamos ante un veterano de origen itálico que habría servido en alguna de las unidades legionarias - III, VI y $X$ - que componían el ejército hispánico. Esta opinión contrasta con la de E. W. Haley, para quien la inscripción de L. Vissellius Niger sería un claro ejemplo del asentamiento de veteranos en el ager Cluniensis en época de Galba (Haley, 1992: 161), propuesta consideraba poco viable por S. Perea Yébenes (1991: 201-202 y 206; 2001: 214). El epitafio de este veterano, cuya presencia en Clunia creemos que debería relacionarse con las necesidades de reclutamiento de finales de la época julio-claudia, fue dedicado por la liberta Publia Caninia Optata.

A estos tres casos debemos añadir un cuarto testimonio procedente de Alburquerque (Badajoz). Allí fue encontrada la dedicatoria funeraria que Valeria Maxsuma realizó en honor de su padre, C. Valerius Maxsumus, veteranus de la legio VII Gemina $\left(\text { n. }^{\circ} 2\right)^{5}$. La paleografía de la inscripción, con la fórmula $D . M$. S., la aparición del nombre completo de la legión y la presencia del calificativo pius sitúan su inscripción hacia mediados del siglo II d. C. Todo ello permitiría suponer que este personaje habría sido reclutado en Caesar Augusta entre finales del siglo I d. C. y comienzos del siglo II d. C., quizás en época del emperador Trajano (Le Roux, 1982: 208, n. ${ }^{\circ}$ 131; Palao Vicente, 2006: 175). Una vez finalizado su periodo de servicio, C. Valerius

\footnotetext{
3 CIL II, 2630: M(arcus) Valerius P(ubli) / f(ilius) Ani(ensi) Secundus / veter(anus) h(ic) s(itus) e(st)

4 HEpOL, 14196: L(ucius) Vissellius / Niger veteranus / Aniensis Caes/araugustanus / h(ic) [s(itus)] e(st) / Publia Canin[i]a / Optata Publi / Canini liberta / d(e) [s(uo) f(aciendum)] c(uravit)

5 HEpOL, 20043: D(is) M(anibus) s(acrum) / C(aius) Valerius / Maxsumus Cae[s]/araugusta veter(anus) / leg(ionis) VII Geminae / Felicis ann(orum) LV / h(ic) s(itus) e(st) s(it) t(ibi) t(erra) l(evis) / Valeria Maxsu/ma patri pio / f(aciendum) c(uravit)
} 
Maxsumus optó por asentarse en la provincia de Lusitania, donde muy posiblemente contrajo matrimonio. Fruto del mismo habría sido su hija Valeria Maxsuma, encargada de dedicar la inscripción.

El último testimonio procedente de la península ibérica hace referencia a un legionario oriundo de Clunia. Se trata de Lucius Aelius Celer (n. $\left.{ }^{0} 1\right)^{6}$, que sirvió durante trece años en la centuria de Claudius Amabilis de la legio VII Gemina. En función de su origo Cluniensis y de la datación propuesta para la inscripción, fechada entre finales del siglo I y comienzos del siglo II d. C., se ha planteado la posibilidad de que L. Aelius Celer hubiese formado parte de la primera leva de la legio VII en tiempos de Galba (Le Roux, 1982: 197; Palao Vicente, 2006: 111). Su inscripción presenta, no obstante, algunos problemas en relación a su procedencia, ya que ha sido asignada tanto a Mérida (consideración realizada por E. Hübner y seguida por otros autores: Haley, 1986: 191, n. ${ }^{\circ}$ 108; Gómez-Pantoja y Castillo Sanz, 2014: 512, n. ${ }^{\circ}$ 12) como a Écija (Roldán Hervás, 1974: 456, n. ${ }^{\circ}$ 592; Le Roux, 1982: 196, n. ${ }^{\circ}$ 90; Palao Vicente, 2006: 308 y 324). Quienes vinculan este testimonio con la capital lusitana han considerado que la presencia de L. Aelius Celer en Augusta Emerita pudo haber estado relacionada con algún tipo de labor administrativa, mientras que quienes sitúan su inscripción en la Bética plantean que este cluniense pudo haber tomado parte en trabajos administrativos o de mantenimiento desarrollados en esta región, como la restauración de la Via Augusta llevada a cabo durante la dinastía flavia (Le Roux, 1982: 197; Palao Vicente, 2006: 308 y 324) (tabla 3).

Tabla 3. Legionarios reclutados en las colonias romanas de la Hispania Citerior cuyas inscripciones proceden de la península ibérica.

\begin{tabular}{|c|c|c|c|c|c|c|c|c|c|c|}
\hline \multirow{2}{*}{$\begin{array}{c}\mathbf{N}^{0} 1 \\
1\end{array}$} & \multirow{2}{*}{$\begin{array}{l}\text { Onomástica } \\
\text { Lucius } \\
\text { Aelius Celer }\end{array}$} & \multicolumn{2}{|c|}{ Unidad y grado } & \multirow{2}{*}{$\begin{array}{l}\text { Cronología } \\
\text { Transición } \\
\text { siglo I al II } \\
\text { d.C. }\end{array}$} & \multicolumn{2}{|c|}{$\begin{array}{l}\text { Años de } \\
\text { servicio y } \\
\text { edad de } \\
\text { muerte }\end{array}$} & \multirow{2}{*}{$\begin{array}{l}\text { Tribu } \\
\text { Galeria }\end{array}$} & \multirow{2}{*}{$\begin{array}{l}\text { Origen } \\
\text { Clunia }\end{array}$} & \multirow{2}{*}{$\begin{array}{c}\text { Lugar de } \\
\text { hallazgo }\end{array}$} & \multirow{2}{*}{$\begin{array}{l}\text { Referencia } \\
\text { CIL II, } \\
\text { 5265; CILA } \\
\text { II, } 703\end{array}$} \\
\hline & & $\begin{array}{c}\text { Legio VII } \\
\text { Gemina }\end{array}$ & Miles & & 13 & ¿30? & & & & \\
\hline 2 & $\begin{array}{c}\text { Caius } \\
\text { Valerius } \\
\text { Maxsumus }\end{array}$ & $\begin{array}{l}\text { Legio VII } \\
\text { Gemina }\end{array}$ & Veteranus & $\begin{array}{l}\text { Mediados } \\
\text { siglo II d.C. }\end{array}$ & & 55 & & $\begin{array}{l}\text { Caesar } \\
\text { Augusta }\end{array}$ & $\begin{array}{c}\text { Alburquerque } \\
\text { (Badajoz) }\end{array}$ & $\begin{array}{l}H E p O L, \\
20043\end{array}$ \\
\hline 3 & $\begin{array}{l}\text { Marcus } \\
\text { Valerius } \\
\text { Secundus }\end{array}$ & $\begin{array}{l}\text { ¿Legio X } \\
\text { Gemina? }\end{array}$ & Veteranus & Siglo I d.C. & & & Aniensis & $\begin{array}{l}\text { Caesar } \\
\text { Augusta }\end{array}$ & Petavonium & $\begin{array}{c}C I L \text { II, } \\
2630\end{array}$ \\
\hline 4 & $\begin{array}{l}\text { Lucius } \\
\text { Vissellius } \\
\text { Niger }\end{array}$ & & Veteranus & $\begin{array}{c}\text { Transición } \\
\text { siglo I al II } \\
\text { d.C. }\end{array}$ & & & Aniensis & $\begin{array}{l}\text { Caesar } \\
\text { Augusta }\end{array}$ & Clunia & $\begin{array}{c}H E p O L, \\
14196\end{array}$ \\
\hline 5 & [---] Tertius & $\begin{array}{c}\text { Legio IIII } \\
\text { Macedonica }\end{array}$ & Veteranus & $\begin{array}{c}\text { Reinado de } \\
\text { Tiberio o } \\
\text { Nerón }\end{array}$ & & 70 & Aniensis & $\begin{array}{l}\text { Caesar } \\
\text { Augusta }\end{array}$ & Vareia & $\begin{array}{c}A E 1997, \\
912\end{array}$ \\
\hline
\end{tabular}

\subsubsection{Fuera de Hispania}

El mayor número de testimonios reunidos en este trabajo procede de fuera de la península ibérica. Se trata de 18 inscripciones que mencionan un total de 20 personajes, distribuidos geográficamente según se muestra en la figura 3. Los datos recogidos permiten agrupar los lugares de destino de estos militares hispanos en cuatro grandes áreas: Britannia, la frontera

6 CIL II, 5265; CILA II, 703: L(ucius) Aelius L(uci) [f(ilius)] / Gal(eria) Celer / Clun(iensis) mil(es) / leg(ionis) VII G(eminae) F(elicis) Cl/audi(ae) Amabi/lis ann(orum) XXX[- - ] / aerorum / XIII h(ic) s(itus) c(arus?) s(uis?) [- - -] 


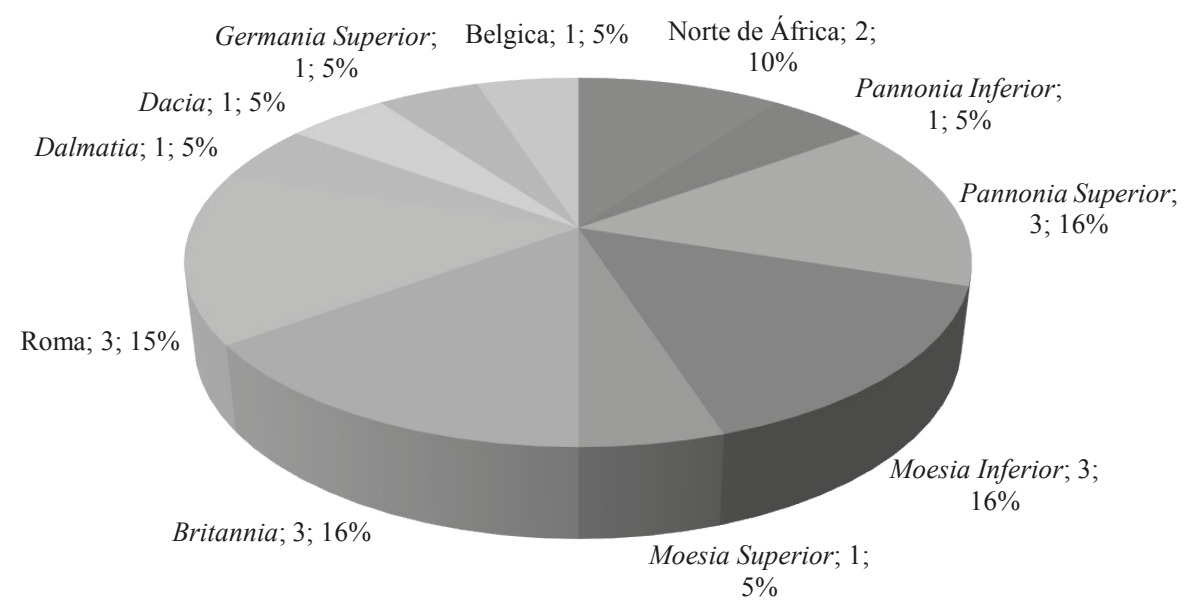

Figura 3. Distribución geográfica de la documentación estudiada en este apartado.

renano-danubiana, el norte de África y Roma. Entre ellas sobresalen Britannia y la capital imperial, que cuentan con tres testimonios cada una, y las regiones de Pannonia y Moesia, con cuatro inscripciones cada una. La procedencia de nuestra documentación epigráfica refleja claramente la disposición del ejército romano desde época augustea, coincidente con las zonas fronterizas del Imperio (sobre la distribución geográfica y la movilidad de las legiones romanas en época altoimperial: Le Bohec, 2000; 2004: 286-287).

\section{Britannia}

Britannia conformaba una compleja zona de frontera a la que Roma destinó importantes medios militares. Sus recursos mineros constituyeron un poderoso aliciente para su conquista, iniciada en tiempos de Claudio y continuada posteriormente bajo los Flavios. Es en este contexto donde debe incardinarse la presencia en la isla de un importante grupo de militares de origen hispano (Gutiérrez Merino, 2002: 229-234). Dentro de este colectivo contamos con tres testimonios vinculados a las colonias de la Citerior. Dos de ellos proceden de Deva Victrix (Chester). Allí fue encontrada la inscripción del salariense Lucius Valerius Pud[ens?] (n. $\left.{ }^{\circ} 22\right)^{7}$. La pérdida de la parte final del epígrafe ha generado dificultades a la hora de fijar algunos de los elementos presentes en el texto conservado. El primero de ellos está conformado por la unidad en la que sirvió este personaje, cuyo nombre se ha perdido. No obstante, la aparición de su inscripción en Deva Victrix, campamento permanente de la legio $X X$, permite suponer que L. Valerius Pud[ens?] habría servido en esta unidad (Malone, 2005: 264-265, n. ${ }^{\circ} 88$ ). El segundo problema consiste en determinar la ciudad de procedencia de este legionario, de la que únicamente se conservan varias letras sueltas. Inicialmente la origo fue reconstruida como [S]ala[p]ia $(R I B, 542)$, ciudad situada en Apulia (Italia). Sin embargo, E. Birley (1986: 205, e) se decantó posteriormente por restituir la origo como [S]ala[r]ia, en referencia a la colonia hispana situada en Úbeda la Vieja (Jaén). Según expuso este autor, la opción de [S]ala[p] ia no tendría demasiado sentido debido al escaso número de soldados procedentes de Apulia que sirvieron en el ejército romano. Por el contrario, Hispania fue una región que aportó un notable número de efectivos a las legiones romanas, al menos hasta época de Trajano, por lo que le resultaba más apropiado identificar la ciudad de procedencia de Valerius Pud[ens?] con

\footnotetext{
7 RIB, 542: Dis Man(ibus) / L(ucius) Valerius L(uci) (filius) / [S]ala[r]ia Pud/[...]III[...] / [...]
} 
Salaria. Su planteamiento ha sido seguido de forma reciente por J. Malone (2005: 265, n. $\left.{ }^{\circ} 88\right)$ y aparece recogido igualmente en la edición digital y actualizada del Roman Inscriptions of Britain (RIB, 542).

También en Deva ha sido hallada la inscripción de Lucius [Elufrius?] Praesens (n. $\left.{ }^{\circ} 12\right)^{8}$. Se trata de una dedicación realizada en honor de Iupiter Tanarus que puede fecharse con certeza en el 154 d. C. gracias a la mención de los cónsules del año. Lucius [Elufrius?] Praesens fue princeps legionis en la legio $X X$, aunque, por lo demás, el texto es bastante corrupto y presenta importantes problemas de lectura. Estos afectan principalmente a la onomástica, donde el nomen propuesto es pura hipótesis, y a la origo, de la que únicamente se conservan las letras finales: [-]unia. Tradicionalmente ha sido reconstruida como [Cl]unia (RIB, 452; Malone, 2005: 121, n. ${ }^{\circ}$ 24), aunque para S. Perea Yébenes (2001: 218, n. ${ }^{\circ} 7$ ) esta restitución resulta dudosa, por lo que, junto con otros elementos como la dedicación a Tanarus y la cronología de la pieza, considera que este personaje no debe ser incluido entre los militares clunienses.

Finalmente, el tercer testimonio procedente de Britannia ha sido localizado en Lindum (Lincoln). Se trata del epitafio de Lucius Sempronius Flavinus, originario de Clunia (n. $\left.{ }^{\circ} 20\right)^{9}$. Falleció a los 30 años tras 7 de servicio en la legio VIIII Hispana. Esta unidad participó en la conquista de Britannia y en la posterior represión de la revuelta encabezada por la reina Boudica. Permaneció en Lindum entre el 48 y el 71 d. C., siendo finalmente estacionada en Eboracum (York) (Rodríguez González, 2001: 270-280). Dado que se trata de un epitafio, la inscripción de L. Sempronius Flavinus debe ser anterior al traslado de la unidad a Eboracum, lo que permite fechar la pieza entre el final de los Julio-Claudios y el comienzo de la dinastía flavia. Por ello es posible que el reclutamiento de este miles hubiese tenido lugar en época de Nerón (Le Roux, 1982: 188, n. ${ }^{\circ}$ 66).

\section{Gallia Belgica}

De Augusta Treverorum (Tréveris, Alemania) procede el epitafio de Titus Lucretius A[---], fechado en el siglo I d. C. $\left(\text { n. }{ }^{\circ} 18\right)^{10}$. El texto tiene una laguna que ha provocado la pérdida del cognomen, para el que S. Perea Yébenes $\left(2001: 216,{ }^{\circ}{ }^{\circ}\right.$ ) ha propuesto diversas reconstrucciones a partir de la primera letra conservada. Este personaje indica su procedencia mediante la expresión ex\{s\} Hispania [cit(eriore) clu]/niensis, lo que no deja lugar a dudas sobre su vinculación con Clunia. Sirvió durante 15 o 25 años en el ala I Hispanorum. Esta unidad auxiliar fue reclutada en la península ibérica en tiempos de Augusto. Se conoce su presencia en Augusta Treverorum en los primeros años del reinado de Tiberio. Posteriormente, quizás bajo Claudio, fue transferida a Burnum (Dalmatia) y, finalmente, a Aquincum (Pannonia) (Roldán Hervás, 1974: 91-93).

\section{Germania Superior}

De Mogontiacum procede la inscripción de Caius Valerius Secundus, fechada a finales del siglo I d. C. $\left(n .^{0} 23\right)^{11}$. Se trata de una estela de piedra en cuya parte superior aparece la figura

\footnotetext{
8 RIB: 452: I(ovi) O(ptimo) M(aximo) Tanaro / L(ucius) [Elufrius(?)] Galer(ia) / Praesens [Cl]unia / pri(nceps) leg(ionis) XX V(aleriae) V(ictricis) / Commodo et / Laterano co(n)s(ulibus) v(otum) s(olvit) l(ibens) m(erito)

9 RIB, 256: L(uci) Semproni Fla/vini mil(i)t(i)s leg(ionis) VIIII / (centuria) Babudi Severi / aer(orum) VII an(n) or(um) XXX / (H)ispani Galeria / Clunia

10 CIL XIII, 11317: T(itus) Lucretius A[- - - f(ilius)] / ex\{s\} Hispania [cit(eriore) clu]/niensis eque[s alae I(?) Hispan]/orum stipe[ndiorum X] / XVh(ic) s(itus) [e(st)]

${ }_{11}$ CIL XIII, 6911: C(aius) Val(erius) C(ai) f(ilius) Ga[l]e[r]i[a] / Secu(n)dus C[l]u[nia mil(es?)] / leg(ionis) XIIII [Gem(inae) Mart(iae) Vict(ricis)] / an(norum) XL sti(pendiorum) XIX h(ic) s(itus) [e(st)]
} 
de un soldado en pie sosteniendo el signum de la legión. Este personaje sirvió en la legio XIIII Gemina Martia Victrix, unidad destinada al limes germano en tiempos de Vespasiano, donde quedó acantonada en Mogontiacum. Caius Valerius Secundus murió a los 40 años tras 19 de servicio, lo que sugiere un reclutamiento en época de Nerón o Vespasiano (Le Roux, 1982: 326). La pertenencia de este personaje a la tribu Galeria ha servido para plantear su origen hispano (Le Roux, 1982: 221, n. ${ }^{\circ} 175$ ). Sin embargo, su procedencia exacta resulta más difícil de determinar, aunque ha sido restituida como C [l] u[nia] (Hernández Guerra, 2017: 392, n. ${ }^{\circ}$ 1). El texto conservado nada dice de la posición de este miles dentro de la legio XIIII, aunque su representación junto al signum en la cabecera de la estela permite suponer que habría desempeñado las tareas de signifer en la referida unidad.

\section{Pannonia}

En esta zona del Imperio contamos con cuatro testimonios procedentes principalmente de Pannonia Superior, concretamente de Carnuntum y de Brigetio. En la primera conocemos a Titus Aurelius Silvanus, natural de Tarraco $\left(n{ }^{\circ} 9\right)^{12}$. Se trata de una inscripción funeraria emplazada probablemente en una tumba familiar donde también fueron enterrados los hijos, muertos todos ellos a una temprana edad, y la esposa de T. Aurelius Silvanus. Este falleció en Carnuntum a los 81 años, por lo que dada su avanzada edad es posible que hubiese sido el último miembro de su familiar en morir. Este personaje se define como magister navaliorum, lo que permite suponer que durante su juventud habría servido en los navalia de la legio XIIII Gemina. Se trataría seguramente de las instalaciones relacionadas con las flotillas fluviales con las que las legiones del Danubio patrullarían dicho río y que pudieron haber tenido una de sus sedes en el puerto de Carnuntum (Reddé, 1986: 301). El empleo del término magister indicaría probablemente que T. Aurelius Silvanus habría sido un oficial de rango elevado dentro de las mismas. Finalmente, conviene señalar que este personaje aparece definido también como veteranus, por lo que habría cumplido la totalidad de años de servicio requeridos y decidido instalarse en Carnuntum tras su licenciamiento. Quizás en esta decisión hubiese tenido algo que ver el hecho de que su esposa, Aelia Iustina, fuese probablemente de origen panonio (Weber, 2010: 207).

De Brigetio proceden los testimonios de Caius Iulius Lupercus (n. $\left.{ }^{\circ} 17\right)$ y Caius Iulius Candidianus (n. ${ }^{\circ}$ 15), documentados en una misma inscripción datada en el siglo II d. C. Ambos personajes comparten origen geográfico, parentesco familiar y oficio militar ${ }^{13}$. La inscripción fue dedicada por Caius Iulius Candidianus a su tío, Caius Iulius Lupercus, fallecido a los 50 años y del que es heredero. Este aparece definido como veteranus, lo que indicaría su carácter de soldado licenciado. Su servicio lo desarrolló en el ala III Thracum, creada probablemente en tiempos de Augusto y que estuvo destinada en Siria antes de tomar parte en las guerras de Trajano en Dacia. Con posterioridad a las mismas habría quedado acantonada en Pannonia, donde se documenta su presencia durante el siglo II d. C. (Zaharide, 2007: 1511-1512). Caius Iulius Candidianus, por su parte, era beneficiarius del legatus de la legio I en el momento en que fue grabada la inscripción. Este tipo de soldados realizaban diversos trabajos en cuarteles al servicio del estado mayor o de uno de los oficiales de este (Carreras Monfort, 1997; Palao

12 CIL II $2 / 14$, E4: T(itus) Aur(elius) Silvanus vet(eranus) ex magistr(o) / navalior(um) leg(ionis) XIIII g(eminae) nation(e) / Hispan(us) Tarraconensis / ann(orum) LXXXI vivus sibi et / Aeliae Iustinae coniug(i) / obsequentissimae et / Aureli(i)s Maximinae an(norum) / VII Marco ann(orum) Vet Floro / ann(orum) V fili(i)s pientissimis / [------] / [------

13 CIL III, 4321: D(is) M(anibus) / C(aio) Iul(io) C(ai) [fi]l(io) / Luperco domo / Sala(ria) vet(eranus) ex dec(urione) / alae III Thra(cum) vixit / an(nos) L C(aius) Iul(ius) Can/didianus b(eneficiarius) leg(ati) / leg(ionis) I Adi(utricis) [P(iae)] F(idelis) / neposqui / et heres / avonculo / pientissimo / f(aciendum) c(uravit) 
Vicente, 2006: 147-158). La legio I fue creada de forma irregular durante la guerra civil del año 69, siendo enviada a Hispania por el emperador Vitelio y trasladada posteriormente por Vespasiano a Germania Inferior, donde fue acantonada en Mogontiacum y, posteriormente, en Brigetio (Rodríguez González, 2001: 32-44).

La origo aparece recogida únicamente en el caso de C. Iulius Lupercus, aunque en base al parentesco familiar que une a ambos personajes podemos suponer que Caius Iulius Candidianus tendría la misma procedencia. Esta aparece indicada mediante la fórmula domo Sala, que puede restituirse como domo Sala(ria) y que haría referencia a la colonia hispana situada en Úbeda la Vieja (Jaén) (EDCS; HEp 14, 2005, 192). Sin embargo, en RHP, 197 y en HD039474 se considera que la indicación de origo se encuentra completa, lo que permitiría vincular a estos personajes con la ciudad norteafricana de Sala (Salé, Marruecos), tal y como claramente se hace en $R H P, 197$. El conjunto epigráfico adscrito a esta ciudad no es muy amplio (78 inscripciones en $E D C S$ ) y aunque en varias inscripciones se constata la $r(e s) p($ ublica) Salensium y el epíteto salenses para referirse a sus habitantes, en ninguna de ellas se menciona el nombre completo de la ciudad, por lo que sería este el primer caso. Por otro lado, la presencia de la gens Iulia, a la que pertenecen ambos personajes, se limita a un único testimonio. Por ello, creemos que resultaría más aceptable la restitución de la origo como domo Sala(ria). Es cierto que la forma de presentar la misma resulta peculiar. Sin embargo, el uso de la expresión domo + la ciudad de origen se documenta en otros casos de emigrantes procedentes de las colonias hispanas ${ }^{14}$. La presencia de la gens Iulia es igualmente limitada en Salaria, cuyo corpus epigráfico es también escaso (18 inscripciones en EDCS). No obstante, quizás podríamos vincular a estos personajes con Marcus Iulius Aemilianus, que fue duumvir en Salaria a mediados del siglo II d. C. (Gimeno Pascual, 2004-2005). Además, el hecho de que se haya documentado a otro hispano, en este caso procedente de Tarraco $\left(C I L \mathrm{II}^{2} / 14,1171\right)$, sirviendo en el ala III Thracum podría apoyar el origen peninsular de C. Iulius Lupercus y de C. Iulius Candidianus.

La última inscripción procedente de Pannonia, en este caso de Pannonia Inferior, es la del Caesaraugustanus Lucius Aurelius Sequens (n. ${ }^{\circ}$ 8), cuyo epitafio fue hallado en Campona y ha sido fechado a comienzos del siglo II d. C. ${ }^{15}$. En él este personaje aparece referido como veteranus de la legio II Adiutrix, lo que indicaría que habría cumplido los veinte años de servicio requeridos. Tras ello habría optado por asentarse en la misma región donde realizó su servicio militar. El lugar de donde procede la inscripción, el campamento de Campona, estaba configurado como un asentamiento de tropas auxiliares que formaba parte de la línea defensiva del limes danubiano. Se encuentra situado a escasa distancia del campamento principal de Aquincum (Budapest), donde seguramente habría estado destinado L. Aurelius Sequens. Su pertenencia a la legio II Adiutrix puede ayudarnos también a determinar su fecha de reclutamiento. Dado que esta unidad fue asentada en Aquincum tras la conquista de la Dacia, la inscripción de este Caesaraugustanus no puede ser anterior al año $106 \mathrm{~d}$. C., por lo que si a esto sumamos su condición de veteranus podemos suponer que L. Aurelius Sequens habría sido reclutado a finales de la dinastía flavia.

\section{Moesia}

Siguiendo el curso del Danubio hacia su desembocadura encontramos la región de Moesia, dividida también en dos provincias, Superior e Inferior. De ella proceden cuatro testimonios.

14 Serían los casos de Baebia Venusta, de Corduba (CIL VI, 34664); Quintus Bruttius Crescens, de Tucci (CIL XIII, 6856); M. Vibius Maurinus, de Emerita (Roldán Hervás, 1974: 453, n. ${ }^{\circ}$ 568); Caenus, de Norba Caesarina (Le Roux, 1982: 189-190, n. ${ }^{\circ} 69$ bis); Lucius Afranius Eros, de Tarraco (CIL XII, 4377).

15 TITAQ, 1009: L(ucius) Aureli/us An(i)ensi\{s\} / Sequens / Caesaraug/ustae vet(eranus) / leg(ionis) II Ad(iutricis) do/nis do[nato] / [ 
En Viminacium (Moesia Superior) ha sido documentado el epitafio de Lucius Caesius Flaccus, natural de Caesar Augusta (n. $\left.{ }^{0} 11\right)^{16}$. La inscripción ha perdido su parte inferior, lo que nos impide concretar datos como la edad de fallecimiento, de la que únicamente se ha conservado el numeral X. Lucius Caesius Flaccus fue centurión en la legio IIII Flavia, por lo que su inscripción debe fecharse con posterioridad al año $86 \mathrm{~d}$. C., momento en que esta unidad fue establecida en Moesia Superior. Para P. Le Roux este personaje habría sido reclutado alrededor del año 100 d. C., lo que estaría en consonancia con la cronología del siglo II d. C. propuesta para su inscripción (Roldán Hervás, 1974: 475, n. ${ }^{\circ}, 727$; Le Roux, 1982: 327). La pérdida de la parte final de la misma nos impide ser más precisos, pues desconocemos los años de servicio. Sí podemos pensar en base al texto conservado que Lucius Caesius Flaccus habría fallecido mientras se encontraba en activo, dado que no se consigna la expresión veteranus. Merece la pena señalar también la peculiar forma en que aparece escrita la origo, pues en la inscripción puede leerse Caesara Aug., en lo que, sin duda, debió ser un error del lapicida o del dedicante del epígrafe, ya que ninguno de los emigrantes procedentes de Caesar Augusta constatados hasta el momento indica así su procedencia. En cualquier caso, creemos que la pertenencia de L. Caesius Flaccus a la tribu Aniensis permite vincularlo con esta colonia hispana (Wiegels, 1985: 101).

Los tres testimonios restantes localizados en Moesia proceden de su provincia Inferior. Dos de ellos están grabados en el Trofeo de Adamklissi, el enorme monumento conmemorativo levantado por Trajano en el año 109 d. C. para celebrar su victoria sobre los dacios en Tapae, lo que nos permite suponer que los milites constatados en él habrían tomado parte en esta confrontación. Allí se encuentran mencionados [---]vius Reburrus (n. $\left.{ }^{\circ} 25\right)^{17}$, natural de Clunia, y Caius Vitellius Seranus (n. $\left.{ }^{\circ} 24\right)^{18}$, cuya origo, restituida como [Ca]es(area), permite considerar que procedía de Caesar Augusta (Roldán Hervás, 1974: 434; Magallón Botaya y Navarro Caballero, 1991-1992: 417). Sin embargo, al igual que ocurre en el caso de $L$. Caesius Flaccus, conviene reseñar la peculiar forma en que ha sido restituida su origo, ya que el término [Ca]es(area) resulta extraño entre los emigrantes de Caesar Augusta. Esto nos permitiría también contemplar otras ciudades, tales como Caesarea o Caesarea Maritima, como posibles lugares de origen de C. Vitellius Seranus.

El tercer testimonio documentado en Moesia Inferior fue encontrado en Novae y conforma el epitafio del cluniense Caius Aurelius Vegetus (n. ${ }^{0}$ 10) ${ }^{19}$. La pieza en cuestión procede del campamento de la legio I Italica y recoge la trayectoria militar de este personaje, estudiada ya en varios trabajos (Kolendo, 2001; Perea Yébenes, 2002: 93-99). En ella destaca su servicio en dos unidades distintas. La primera de ellas fue un cuerpo de carácter auxiliar, la Cohors $V$ Asturum, desde donde posteriormente fue transferido a la legio I Italica, con la que sirvió en Moesia en época flavia. En consecuencia, los 23 años de servicio que constan en la inscripción deben entenderse como la suma de los desarrollados tanto en la V Asturum como en la I Italica. El paso de una unidad a otra, algo poco frecuente, debería incardinarse en las circunstancias extraordinarias derivadas de la guerra civil del año 69 d. C. (Kolendo, 2001: 529-530), siendo posible que el alistamiento de C. Aurelius Vegetus en la V Asturum hubiese tenido lugar con anterioridad a la promoción colonial de Clunia (Perea Yébenes, 2002: 98-99).

\footnotetext{
16 CIL III, 14511: L(ucius) Caesius L(uci) f(ilius) / Anie(nsi) Flaccus / Caesara Aug(usta) / (centurio) leg(ionis) IIII F(laviae) F(elicis) vix(it) / [a]nn(os) X[

17 CIL III, 14214: [- - ] vius Reburus Cluni(a)

18 CIL III, 14214: C(aius) Vitellius Sera[nus Ca]es(area)

19 AE 1999, 1333: C(aius) Aurelius / [- -] f(ilius) G[a]leria / Vegetus Clu(nia) / mil(es) leg(ionis) I I(talicae) F() R() / stip(endiorum) XXIII ann(orum) XL / milit(avit) in coh(orte) / V Ast(urum) ind(e) / translat(us) / in leg(ionem) I It(alicam) / h(ic) s(itus) e(st) / ex t[estamento(?)]
} 


\section{Dacia}

El único testimonio que hemos documentado en Dacia procede de Apulum-Alba Iulia y hace referencia al veteranus Cluniensis Lucius Iulius Leuganus $\left(\mathrm{n}^{\circ}{ }^{\circ} 16\right)^{20}$. Se trata de un ara consagrada a la Victoria Augusta que fue levantada a comienzos del siglo II d. C. L. Iulius Leuganus sirvió en la legio XIIII Gemina, unidad conocida por su implicación en la fracasada rebelión de Antonius Saturninus (89 d. C.). Con posterioridad, intervino en la conquista de la Dacia, siendo acantonada al término de la misma en Apulum (Rodríguez González, 2001: 337). Es posible que L. Iulius Leuganus hubiese participado en buena parte de estos acontecimientos, dado que su reclutamiento pudo haber tenido lugar en época de Nerón (Perea Yébenes, 2001: 217) o al comienzo de la dinastía flavia (Le Roux, 1982: 219, n. ${ }^{\circ} 167$; Haley, 1992: 160, nota 7). Tras su retiro fue asentado como colono en Apulum (Le Roux, 1982: 219, n. ${ }^{\circ}$ 167), donde probablemente contrajo matrimonio, dado que fue su hijo, también militar, el encargado de consagrar su inscripción funeraria.

\section{Dalmatia}

En la región de Dalmatia contamos únicamente con un testimonio, procedente en este caso de Burnum, campamento romano situado $6,5 \mathrm{~km}$ al norte de Kistanje (Croacia). Allí fue localizado el epitafio del Caesaraugustanus Lucius Icconius Surio (n. $\left.{ }^{\circ} 14\right)^{21}$. Este personaje sirvió durante 23 años en la centuria de Titus Silvanus de la legio XI Claudia. Desconocemos su edad de fallecimiento, aunque es posible que estuviera entre los 40 y los 50 años en función del momento de reclutamiento, que habría tenido lugar posiblemente en época de Claudio (Le Roux, 1982: 187 y 325). La inscripción, que fue dedicada por el heredero del difunto, se sitúa cronológicamente entre el reinado del emperador Claudio, que otorgó a la legio XI el sobrenombre de Claudia en el año 42 d. C. (Rodríguez González, 2001: 310), y el comienzo del reinado de Vespasiano, bajo cuyo mandato esta unidad fue trasladada a Germania en el año 70 d. C. (Le Roux, 1982: 187; Rodríguez González, 2001: 311). Dado que la inscripción de este Caesaraugustanus es de carácter funerario, hemos de suponer que su fallecimiento tuvo lugar con anterioridad al traslado de la legión a la frontera del Rhin.

\section{Norte de África}

En el norte de África, concretamente en la zona de Numidia, contamos con la presencia de dos milites originarios de Clunia. La inscripción más antigua es la de Caius Antonius Maternus (n. ${ }^{\circ}$ 7), centurión de la legio III Augusta, cuyo testimonio procede de Lambaesis (Tazoult-Lambèse, Argelia) ${ }^{22}$. Es posible que hubiera servido con anterioridad en Hispania (Le Roux, 1982: 300; Le Bohec, 1989: 159; Perea Yébenes, 2001: 217, n. ${ }^{\circ}$ 4), donde habría sido reclutado. La fecha de la inscripción ha suscitado algunas diferencias en la historiografía entre quienes la sitúan a finales del siglo I o comienzos del II d. C., lo que indicaría que C. Antonius Maternus habría estado en activo en la última parte del siglo I d. C. (Le Bohec, 1989: 159; Perea Yébenes, 2001: 217, n. ${ }^{\circ}$ 4), y quienes retrasan este epitafio hasta mediados del siglo II d.

20 CIL III, 1158: Victorae / Aug(ustae) / L(ucius) Iul(ius) L(uci) (!) Galer(ia) / Leuganus / Clunia vet(eranus) leg(ionis) / XIIII G(eminae) M(artiae) V(ictricis) aedis / custos c(ivium) R(omanorum) leg(ionis) XIII [G(eminae)] / nomine suo et / C(ai) Iul(i) Paterni fili(i) / sui d(onum) d(edit)

${ }_{21}$ CIL III, 6417: L(ucius) Icconius L(uci) f(ilius) / Ani(ensis) Surio Cae/saraug(usta) miles / leg(ionis) XI C(laudiae) p(iae) f(idelis) / [|(centuria)] Titi Silvani / stip(endiorum) XXIII t(estamento) f(ieri) i(ussit) / h(eres) f(aciendum) c(uravit)

22 CIL VIII, 2807: C(aius) Antonius / Maternus / domo Clunia / (centurio) leg(ionis) III Aug(ustae) / hic situs est 
C., planteando, en consecuencia, que el reclutamiento de este personaje habría tenido lugar a comienzos de dicha centuria (Le Roux, 1982: 299, 327).

Algo posterior es el testimonio de Caius Aemilius Serenus, datado en la segunda mitad del siglo II d. C. (n. $\left.{ }^{\circ} 6\right)^{23}$. El epitafio de este veteranus de la legio VII Gemina fue encontrado en Timgad. Su presencia en esta zona del Imperio debe ponerse en relación con el envío a Numidia de varias vexillationes de la VII Gemina entre los reinados de Adriano y Antonino Pio (Palao Vicente, 1998; 2006: 74-81). Estas habrían sido acantonadas seguramente en Lambaesis, campamento principal de la legio III Augusta. La aparición del epitafio de C. Aemilius Serenus en Thamugadi indicaría que su establecimiento en esta ciudad fue consecuencia de una decisión personal tomada tras haber cumplido su periodo de servicio, consideración que se vería reforzada por su condición de veteranus. En esta decisión debieron influir las oportunidades que ofrecía esta ciudad y también las relaciones sociales establecidas durante su periodo de servicio (Le Roux, 1982: 203, n. ${ }^{\circ}$ 113; Palao Vicente, 2006: 81). Conviene indicar en este sentido la presencia como dedicantes de la inscripción de Sabinus et focaria. El primero es posible que fuese un esclavo, mientras que el segundo término puede emplearse como sinónimo de concubina o compañera (Palao Vicente, 2006: 363 y 373).

\section{Roma}

Finalmente, conocemos la presencia en la capital imperial de tres individuos originarios de las colonias de la Citerior. En los momentos finales del siglo I d. C. podemos encuadrar los testimonios de Caius Fabius Crispus, natural de Carthago Nova (n. $\left.{ }^{\circ} 13\right)^{24}$, y de Staius Saturninus, originario de Clunia (n. $\left.{ }^{\circ} 21\right)^{25}$. El primero de ellos falleció en Roma tras haber servido como speculator en las cohortes pretorianas durante 13 años, con lo cual creemos que la edad de 22 años propuesta tradicionalmente para su fallecimiento debería ser corregida al alza. Sus tareas como speculator resultan difíciles de definir, ya que en muchos casos estas estuvieron relacionadas con aspectos administrativos, sobre todo en el ámbito provincial, aunque también sabemos que los speculatores sirvieron como correos, verdugos y a veces también como escolta (Palao Vicente, 2006: 159-162). Por su parte, Staius Saturninus aparece documentado en un diploma militar que nos permite conocer su servicio en la Cohors II Praetoria. La inscripción ha sido fechada en el año 78 o 79 d. C., por lo que este personaje habría sido reclutado durante el reinado de Nerón (Perea Yébenes, 2001: 215).

Algo posterior es la inscripción de Titus Popilius Brocchus (n. $\left.{ }^{\circ} 19\right)^{26}$, que ha sido fechada en la primera mitad del siglo II d. C. Este personaje sirvió en la centuria de Gradivus de la Cohors III Praetoria. El epígrafe que lo documenta recoge la dedicatoria realizada por este Caesaraugustanus junto con otro personaje llamado Quintus Rosinius Severus, originario de la ciudad itálica de Mutina, en honor del dios Esculapio. Dicha dedicación fue consagrada con posterioridad a la obtención de la honesta missio, lo que permite considerar a este personaje

${ }^{23}$ AE 1934, 36: C(aio) Aemilio / Sereno / vet(erano) leg(ionis) VII / Gem(inae) Fel(icis) / Hispano / G(aleria) Clunia / Sabinus / et Focaria

${ }_{24}$ CIL VI, 2607: C(aius) Fabius / C(ai) f(ilius) Ser(gia) / Crispus / Carthag(ine) / specul(ator) / coh(ortis) VI pr(aetoriae) / (centuria) Flegeri / mil(itavit) an(nos) XIII(?) / vix(it) an(nos) XXII(?) / heres / ex volunt(ate) / p(osuit)

${ }_{25}$ CIL XVI, 25: ] / habent si qui eorum feminam peregrinam / duxerit dumtaxat singuli singulas quas / primo duxerint cum iis habeant conubium / hoc quoque iis tribuo ut quos agros a me / acceperint quasve res possederunt III K(alendas) / [I] anuar(ias) Sex(to) Marcio Prisco Cn(aeo) Pinario / Aemilio Cicatricula co(n)s(ulibus) sint immunes / [---] Stai C(ai) f(ilii) Galeria Saturnini / [C]lunia c(o)ho(rs) II pr(aetoria)

${ }_{26}$ CIL VI, 9 y 30683: Aesculapio sac(rum) / ex voto suscepto / missi honesta miss(ione) / ex coh(orte) III pr(aetoria) |(centuria) Gradivi / Q(uintus) Rosinius Q(uinti) fil(ius) Pol(lia) / Severus Mutina / T(itus) Popilius T(iti) fil(ius) Ani(iensi) / Brocchus / Caesaraug(usta) 
Tabla 4. Legionarios y auxiliares reclutados en las colonias romanas de la Hispania Citerior cuyas inscripciones han sido halladas fuera de la península ibérica.

\begin{tabular}{|c|c|c|c|c|c|c|c|c|c|c|}
\hline \multirow{2}{*}{$\begin{array}{c}\mathbf{N}^{0} 1 \\
6 \\
6\end{array}$} & \multirow{2}{*}{$\begin{array}{l}\text { Onomástica } \\
\text { Caius Aemilius } \\
\text { Serenus }\end{array}$} & \multicolumn{2}{|c|}{ Unidad y grado } & \multirow{2}{*}{$\begin{array}{l}\text { Cronología } \\
\text { Segunda } \\
\text { mitad siglo } \\
\text { II d.C. }\end{array}$} & \multicolumn{2}{|c|}{$\begin{array}{l}\text { Años de } \\
\text { servicio y } \\
\text { edad de } \\
\text { muerte }\end{array}$} & \multirow{2}{*}{$\begin{array}{l}\text { Tribu } \\
\text { Galeria }\end{array}$} & \multirow{2}{*}{$\begin{array}{l}\text { Origen } \\
\text { Clunia }\end{array}$} & \multirow{2}{*}{ 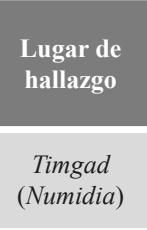 } & \multirow{2}{*}{$\begin{array}{c}\text { Referencia } \\
\text { AE } 1934, \\
36\end{array}$} \\
\hline & & $\begin{array}{l}\text { Legio VII } \\
\text { Gemina }\end{array}$ & Veteranus & & & & & & & \\
\hline 7 & $\begin{array}{c}\text { Caius } \\
\text { Antonius } \\
\text { Maternus }\end{array}$ & $\begin{array}{l}\text { Legio III } \\
\text { Augusta }\end{array}$ & Centurio & $\begin{array}{c}\text { Transición } \\
\text { siglo I al II } \\
\text { d.C. }\end{array}$ & & & & Clunia & $\begin{array}{l}\text { Lambaesis } \\
\text { (Numidia) }\end{array}$ & $\begin{array}{l}\text { CIL VIII, } \\
2807\end{array}$ \\
\hline 8 & $\begin{array}{l}\text { Lucius } \\
\text { Aurelius } \\
\text { Sequens }\end{array}$ & $\begin{array}{l}\text { Legio II } \\
\text { Adiutrix }\end{array}$ & Veteranus & $\begin{array}{c}\text { Comienzos } \\
\text { del siglo II } \\
\text { d.C. }\end{array}$ & & & Aniensis & $\begin{array}{l}\text { Caesar } \\
\text { Augusta }\end{array}$ & $\begin{array}{l}\text { Campona } \\
\text { (Pan. Inf.) }\end{array}$ & $\begin{array}{c}\text { TITAQ } \\
1009\end{array}$ \\
\hline 9 & $\begin{array}{l}\text { Titus Aurelius } \\
\text { Silvanus }\end{array}$ & $\begin{array}{c}\text { Legio XIIII } \\
\text { Gemina }\end{array}$ & $\begin{array}{l}\text { Veteranus } \\
\text { ex magistro } \\
\text { navaliorum }\end{array}$ & $\begin{array}{l}\text { Segunda } \\
\text { mitad del s. } \\
\text { II d.C. }\end{array}$ & & 81 & & Tarraco & $\begin{array}{l}\text { Carnuntum } \\
\text { (Pan. Sup.) }\end{array}$ & $\begin{array}{c}C I L \mathrm{II}^{2} / 14 \\
\mathrm{E} 4\end{array}$ \\
\hline 10 & $\begin{array}{c}\text { Caius Aurelius } \\
\text { Vegetus }\end{array}$ & $\begin{array}{c}\text { Cohors V } \\
\text { Asturum / } \\
\text { Legio I Italica }\end{array}$ & Miles & $\begin{array}{l}\text { Finales del } \\
\text { s. I d.C. }\end{array}$ & 23 & 40 & Galeria & Clunia & $\begin{array}{c}\text { Novae } \\
\text { (Moe. Inf.) }\end{array}$ & $\begin{array}{c}A E 1999, \\
1333\end{array}$ \\
\hline 11 & $\begin{array}{c}\text { Lucius Caesius } \\
\text { Flaccus }\end{array}$ & $\begin{array}{l}\text { Legio IIII } \\
\text { Flavia }\end{array}$ & Centurio & Siglo II d.C. & & & Aniensis & $\begin{array}{l}\text { Caesar } \\
\text { Augusta }\end{array}$ & $\begin{array}{l}\text { Viminacium } \\
\text { (Moe. Sup.) }\end{array}$ & $\begin{array}{c}C I L \text { III } \\
14511\end{array}$ \\
\hline 12 & $\begin{array}{c}\text { Lucius } \\
\text { [Elufrius?] } \\
\text { Praesens }\end{array}$ & $\begin{array}{c}\text { XX Valeria } \\
\text { Victrix }\end{array}$ & $\begin{array}{l}\text { Princeps } \\
\text { legionis }\end{array}$ & $\begin{array}{l}\text { Año } 154 \\
\text { d.C. }\end{array}$ & & & Galeria & Clunia & $\begin{array}{c}\text { Deva Victrix } \\
\text { (Britannia) }\end{array}$ & $R I B, 452$ \\
\hline 13 & $\begin{array}{l}\text { Caius Fabius } \\
\text { Crispus }\end{array}$ & $\begin{array}{l}\text { Cohors VI } \\
\text { Praetoria }\end{array}$ & Speculator & $\begin{array}{l}\text { Finales del } \\
\text { siglo I d.C. }\end{array}$ & ¿13? & $i^{22} ?$ & Sergia & $\begin{array}{l}\text { Carthago } \\
\text { Nova }\end{array}$ & Roma & $\begin{array}{c}C I L \text { VI, } \\
2607\end{array}$ \\
\hline 14 & $\begin{array}{c}\text { Lucius } \\
\text { Icconius Surio }\end{array}$ & $\begin{array}{c}\text { Legio XI } \\
\text { Claudia Pia } \\
\text { Fidelis }\end{array}$ & Miles & $\begin{array}{l}\text { Mediados } \\
\text { del siglo I } \\
\text { d.C. }\end{array}$ & 23 & & Aniensis & $\begin{array}{c}\text { Caesar } \\
\text { Augusta }\end{array}$ & $\begin{array}{c}\text { Burnum } \\
\text { (Dalmatia) }\end{array}$ & $\begin{array}{l}\text { CIL III, } \\
6417\end{array}$ \\
\hline 15 & $\begin{array}{l}\text { Caius Iulius } \\
\text { Candidianus }\end{array}$ & $\begin{array}{l}\text { Legio I } \\
\text { Adiutrix }\end{array}$ & Beneficiarius & $\begin{array}{l}\text { Segunda } \\
\text { mitad del s. } \\
\text { II d.C. }\end{array}$ & & & & Salaria & $\begin{array}{c}\text { Brigetio } \\
\text { (Pan. Sup.) }\end{array}$ & $\begin{array}{c}C I L \text { III, } \\
4321\end{array}$ \\
\hline 16 & $\begin{array}{l}\text { Lucius Iulius } \\
\text { Leuganus }\end{array}$ & $\begin{array}{c}\text { Legio XIIII } \\
\text { Gemina } \\
\text { Martia Victrix }\end{array}$ & Veteranus & Siglo II d.C. & & & Galeria & Clunia & $\begin{array}{c}\text { Alba Iulial } \\
\text { Apulum } \\
\text { (Dacia) }\end{array}$ & $\begin{array}{c}C I L \text { III, } \\
1158\end{array}$ \\
\hline 17 & $\begin{array}{l}\text { Caius Iulius } \\
\text { Lupercus }\end{array}$ & $\begin{array}{c}\text { Ala III } \\
\text { Thracum }\end{array}$ & $\begin{array}{c}\text { Veteranus ex } \\
\text { decurione }\end{array}$ & $\begin{array}{l}\text { Segunda } \\
\text { mitad del s. } \\
\text { II d.C. }\end{array}$ & & 50 & & Salaria & $\begin{array}{c}\text { Brigetio } \\
\text { (Pan. Sup.) }\end{array}$ & $\begin{array}{c}C I L \text { III, } \\
4321\end{array}$ \\
\hline 18 & $\begin{array}{c}\text { Titus Lucretius } \\
\text { A[-- - }]\end{array}$ & $\begin{array}{c}\text { Ala I } \\
\text { Hispanorum }\end{array}$ & Eques & Siglo I d.C. & $\begin{array}{c}\text { ¿15? } \\
/ \\
\text { ¿25? }\end{array}$ & & & Clunia & $\begin{array}{c}\text { Augusta } \\
\text { Treverorum } \\
\text { (Gallia } \\
\text { Belgica) }\end{array}$ & $\begin{array}{c}\text { CIL XIII, } \\
11317\end{array}$ \\
\hline 19 & $\begin{array}{l}\text { Titus Popilius } \\
\text { Brocchus }\end{array}$ & $\begin{array}{l}\text { Cohors III } \\
\text { Praetoria }\end{array}$ & Veteranus & $\begin{array}{l}\text { Primera } \\
\text { mitad del s. } \\
\text { II d.C. }\end{array}$ & & & Aniensis & $\begin{array}{l}\text { Caesar } \\
\text { Augusta }\end{array}$ & Roma & $\begin{array}{c}C I L \text { VI, } 9 \text { y } \\
30683\end{array}$ \\
\hline 20 & $\begin{array}{l}\text { Lucius } \\
\text { Sempronius } \\
\text { Flavinus }\end{array}$ & $\begin{array}{c}\text { Legio VIIII } \\
\text { Hispana }\end{array}$ & Miles & Siglo I d.C. & 7 & 30 & Galeria & Clunia & $\begin{array}{c}\text { Lindum } \\
\text { (Britannia) }\end{array}$ & $R I B, 256$ \\
\hline 21 & $\begin{array}{c}\text { Staius } \\
\text { Saturninus }\end{array}$ & $\begin{array}{l}\text { Cohors II } \\
\text { Praetoria }\end{array}$ & & $\begin{array}{c}\text { Año } 78 \text { o } 79 \\
\text { d.C. }\end{array}$ & & & Galeria & Clunia & Roma & $\begin{array}{c}\text { CIL XVI, } \\
25\end{array}$ \\
\hline 22 & $\begin{array}{l}\text { Lucius } \\
\text { Valerius } \\
\text { Pudens }\end{array}$ & $\begin{array}{c}\text { Legio XX } \\
\text { Valeria Victrix }\end{array}$ & ¿Miles? & $\begin{array}{c}\text { Siglos I-II } \\
\text { d.C. }\end{array}$ & & & & Salaria & $\begin{array}{c}\text { Deva Victrix } \\
\text { (Britannia) }\end{array}$ & $R I B, 542$ \\
\hline 23 & $\begin{array}{l}\text { Caius Valerius } \\
\text { Secundus }\end{array}$ & $\begin{array}{c}\text { Legio XIIII } \\
\text { Gemina } \\
\text { Martia Victrix }\end{array}$ & $\begin{array}{l}\text { Miles / } \\
\text { signifer }\end{array}$ & Siglo II d.C. & 19 & 40 & Galeria & ¿Clunia? & $\begin{array}{c}\text { Mogontiacum } \\
\text { (Germania } \\
\text { Superior) }\end{array}$ & $\begin{array}{l}\text { CIL XIII, } \\
6911\end{array}$ \\
\hline 24 & $\begin{array}{l}\text { Caius Vitellius } \\
\text { Seranus }\end{array}$ & & Miles & 109 d.C. & & & & $\begin{array}{l}\text { ¿Caesar } \\
\text { Augusta? }\end{array}$ & $\begin{array}{c}\text { Adamklissi } \\
\text { (Moe. Inf.) }\end{array}$ & $\begin{array}{c}C I L \text { III, } \\
14214\end{array}$ \\
\hline 25 & $\begin{array}{l}\text { [---]vius } \\
\text { Reburrus }\end{array}$ & & Miles & 109 d.C. & & & & Clunia & $\begin{array}{l}\text { Adamklissi } \\
\text { (Moe. Inf.) }\end{array}$ & $\begin{array}{c}C I L \text { III } \\
14214\end{array}$ \\
\hline
\end{tabular}


como un veteranus de las cohortes pretorianas. Es posible que nos encontremos ante un voto de agradecimiento por haber sido licenciado con salud. Aunque no se consignan los años de servicio, la referencia a la obtención de la honesta missio permite suponer que T. Popilius Brocchus habría cumplido al menos los dieciséis años de servicio estipulados por Augusto para los miembros del pretorio (Durry, 1968: 262-264 y 290-293) (Tabla 4).

\section{CONCLUSIONES}

De las diez colonias existentes en la Hispania Citerior únicamente cinco han aportado legionarios a este estudio: Caesar Augusta, Carthago Nova, Clunia, Salaria y Tarraco. La documentación relativa a cada una de ellas está condicionada en buena medida por la propia evolución histórica de estas ciudades. Dejando a un lado el caso de Salaria, una colonia de pequeño tamaño cuya documentación es limitada, existe una gran diferencia entre aquellas ciudades, como Carthago Nova y Tarraco, que se configuraron como centros principalmente receptores de la emigración, tanto hispana como extrapeninsular, y aquellas otras, como Caesar Augusta y Clunia, cuyos habitantes parecen tener una especial tendencia hacia la emigración (Gómez-Pantoja, 1999; Ortiz Córdoba, 2019), canalizada principalmente a través de su servicio en el ejército (Perea Yébenes, 2001).

Los hispanos documentados en este trabajo aparecen sirviendo en doce unidades legionarias distintas, a las que debemos añadir tres cuerpos auxiliares y las cohortes pretorianas de Roma (tabla 2). Tres de estas legiones, la VII Gemina, la IIII Macedonica y la X Gemina, tuvieron una especial relación con la península ibérica. La primera fue, de hecho, creada en suelo hispano y estuvo acantonada allí durante buena parte de su historia. Las otras dos, que también formaron parte del ejército romano asentado en Hispania, participaron en la fundación de algunas de las colonias peninsulares. Entre ellas destaca el caso de Caesar Augusta, colonia para la que contamos con cuatro veterani documentados en la península ibérica. Tres de ellos, M. Valerius Secundus, [---] Tertius y L. Vissellius Niger, creemos que pueden ser identificados como descendientes de los primeros colonos asentados en Caesar Augusta. Dicha vinculación puede realizarse a partir de la temprana fecha de los epígrafes y del hecho de que tanto $\mathrm{M}$. Valerius Secundus como [---] Tertius hubiesen sido reclutados para servir en las legiones con que las que se fundó la ciudad, quizás las mismas unidades en las que sirvieron sus padres, prueba de que la incorporación de los hijos al oficio militar fue una de las vías seguidas por Augusto para provincializar el ejército hispano (Espinosa Ruiz, 1990: 11-12). En el caso de L. Vissellius Niger su vinculación con la deductio fundacional de Caesar Augusta puede hacerse a partir de su onomástica, de raíz itálica y escasamente documentada en Hispania.

Geográficamente, los testimonios reunidos en este trabajo pueden dividirse en dos grandes grupos según provengan de Hispania, donde contamos con cinco testimonios, o de las provincias extra-peninsulares, de donde proceden los veinte ejemplos restantes. En el caso de los milites documentados en Hispania su presencia se concentra mayoritariamente en la Hispania Citerior, de donde proceden tres testimonios, mientras que un cuarto corresponde a Lusitania. La inscripción restante presenta problemas de adscripción y ha sido vinculada tanto a Augusta Emerita como a Astigi (tabla 3). En lo que se refiere a los destinos extra-peninsulares destacan las regiones de Moesia y Pannonia, con cuatro testimonios cada una, Roma y Britannia, con tres, y el norte de África, donde conocemos dos casos (gráfico 3).

Las inscripciones reunidas en este trabajo son en su mayoría funerarias. En general su tipología epigráfica es simple: recogen la onomástica del individuo, la tribu en caso de que la consigne, su ciudad de origen, el grado y unidad en la que sirvió y, finalmente, la edad de 
fallecimiento y los años de servicio, que suelen contarse en stipendia o bien en aera. En caso de haberlos se mencionan también los dedicantes y los herederos. Únicamente se separan de esta pauta los testimonios de Lucius [Elufrius?] Praesens, L. Iulius Leuganus y T. Popilius Brocchus, que constituyen tres inscripciones de carácter votivo. La primera está dedicada a Júpiter Tanarus, un culto de ascendencia celta (Malone, 2005: 122), mientras que las otras dos conforman un ara consagrada a la Victoria Augusta y un voto en honor de Esculapio como agradecimiento por haber sido licenciado con salud.

En lo que se refiere a los rangos constatados no hay gran diversidad. En primer lugar conviene señalar que 10 de los 25 milites documentados indican su condición de veterani, lo que significa que habían cumplido su periodo de servicio y recibido, en consecuencia, la correspondiente compensación en forma de tierras o de una suma de dinero en metálico. El resto de personajes hemos de suponer que habrían fallecido mientras aún se encontraban en activo. De ellos, únicamente siete alcanzaron un rango superior al de simple miles. En concreto, contamos con un signifer, Caius Valerius Secundus, originario probablemente de C[l]u[nia], que desempeñó esta importante labor en la legio XIIII, y dos centuriones, Caius Antonius Maternus, también de Clunia, que sirvió en la III Augusta, y Lucius Caesius Flaccus, de Caesar Augusta, que hizo lo propio en la IIII Flavia. Junto a ellos debemos reseñar los casos de Lucius [Elufrius?] Praesens, natural de Clunia, que fue princeps legionis de la XX Valeria Victrix, de Caius Iulius Crispus, procedente de Carthago Nova, que fue speculator en la Cohors VI Praetoria, y de Caius Iulius Candidianus, originario probablemente de Salaria, que alcanzó la privilegiada posición de beneficiarius en la I Adiutrix. Es muy posible que las obligaciones desarrolladas por estos dos últimos personajes hubieran trascendido el ámbito puramente militar e implicado el desarrollo de tareas administrativas. Finalmente, debemos señalar dos casos peculiares. El primero es el del Tarraconensis Titus Aurelius Silvanus, que fue magister navaliorum en la legio XIIII Gemina. Su testimonio resulta sumamente interesante por ser el único de todos los documentados en el que su protagonista estaría relacionado con la marina, en este caso con algunas de las flotillas fluviales que protegían la ribera del Danubio. Su definición como magister sugiere que habría sido un oficial de cierto rango, aunque también podría pensarse en su figura como la de un instructor. El segundo es el del cluniense Caius Aurelius Vegetus, que sirvió en dos unidades distintas, una de carácter auxiliar, la cohors V Asturum, y otra legionaria, la legio I Italica, hecho bastante peculiar que ha sido asociado con las circunstancias extraordinarias que generó la guerra civil del $69 \mathrm{~d}$. C.

En relación a la trayectoria vital de estos hispanos tras su salida del ejército la información que poseemos no es muy abundante, aunque aporta algunos datos interesantes en lo que se refiere a la situación familiar de los diez veterani documentados. Todos ellos optaron por establecerse en las ciudades o regiones donde desarrollaron su periodo de servicio. Su incorporación a la vida civil puede observarse a través del establecimiento de relaciones afectivas, entre las que destaca particularmente el matrimonio, uno de los principales mecanismos de reintegración en la vida civil para los veteranos del ejército, sobre todo si su lugar de asentamiento no se correspondía con su lugar de nacimiento. Sin embargo, ninguno de ellos consigna el desarrollo posterior de una carrera pública en sus lugares de retiro. Dentro de la muestra reunida hemos documentado este tipo de unión en los casos de T. Aurelius Silvanus y C. Valerius Maxsumus. El primero de ellos se retiró en Carnuntum (Pannonia), donde sabemos que formó una familia, dado que está enterrado junto a su esposa y sus hijos, que murieron todos ellos antes que él, en una misma sepultura familiar. Su caso es, además, paradigmático, dado que su esposa, Aelia Iustina, era probablemente de origen panonio (Weber, 2010: 207), lo que, sin duda, habría sido determinante para que este veteranus hubiese optado por asentarse en la región en la que sirvió en lugar de retornar a su Tarraco natal. El segundo, por su parte, habría 
servido seguramente en Augusta Emerita, aunque su inscripción procede de Alburquerque (Badajoz). Tras su retiro habría contraído matrimonio o, al menos, establecido algún tipo de unión sentimental. Fruto de ella fue su hija Valeria Maxsuma, encargada de consagrar la inscripción funeraria de su padre. Una dinámica parecida podemos suponer en el caso de L. Iulius Leuganus, asentado posiblemente como colono en Apulum (Dacia) al final de las guerras de Trajano. En su caso no existe ninguna referencia en su inscripción a su esposa o compañera, aunque el hecho de que fuese su hijo, también militar, el encargado de levantar su epitafio permite suponer que tras su retiro ese veterano cluniense habría establecido algún tipo de unión sentimental en su nueva ciudad. En otras ocasiones, sin embargo, este tipo de uniones presentan un carácter distinto, como podemos observar en el caso de C. Aemilius Serenus, veterano de la VII Gemina documentado en Timgad, en cuya inscripción aparece el término focaria, que puede emplearse dentro de los ambientes castrenses como sinónimo de concubina o compañera (Palao Vicente, 2006: 363 y 373).

En última instancia llaman la atención las diferencias existentes entre las provincias hispanas en lo que a reclutamientos militares se refiere. La primera de ellas estriba en el número de reclutas aportados por las colonias de cada una de las provincias. En este campo son las colonias de Lusitania y la Citerior las que mayor número de inscripciones proporcionan, hecho bastante destacable en el caso de la primera dado su pequeño tamaño y el escaso número de colonias con que contaba. Esto podría indicar la pervivencia de una cierta tradición militar en algunas colonias de estas provincias, cuyo nivel de romanización era más bajo sobre todo en zonas del interior y del noroeste, donde la importancia del ejército como instrumento de integración y promoción social sería mayor que en una región más romanizada como la Bética. La segunda gran diferencia alude a la distribución geográfica de los testimonios estudiados en cada una de estas provincias, dado que los milites procedentes de las colonias béticas y lusitanas sirvieron, salvo contadas excepciones, en provincias situadas en la parte occidental del Imperio; por el contrario, los legionarios oriundos de las colonias de la Hispania Citerior estuvieron destinados mayoritariamente en provincias del sector oriental, principalmente en la zona danubiana. Precisamente su concentración en esta zona es el tercer elemento diferencial, ya que contrasta con la dispersión de la documentación epigráfica relacionada con las colonias de la Bética y la Lusitania, presente en prácticamente todas las zonas fronterizas del Imperio.

\section{BIBLIOGRAFÍA}

Abascal Palazón, J. M. (1994): Los nombres personales en las inscripciones latinas de Hispania, Murcia, Universidad de Murcia.

Abásolo, J. A. (1994): «Sobre algunas escuelas hispanorromanas». BSEAAV, 60: 187-224.

Andreu Pintado, J. (2008): «Sentimiento y orgullo cívico en Hispania: en torno a las menciones de origo en la Hispania Citerior». Gerión, 26 (1): 349-378.

Birley, E. (1986): «Some miltary inscripcións from Chester (Deva)». ZPE, 64: 201-208.

Carreras Monfort, C. (1997): «Los beneficiarii y la red de aprovisionamiento militar de Britannia e Hispania». Gerión, 15: 151-176.

Castillo, C. (1988): «La tribu Galeria en Hispania: ciudades y ciudadanos», J. González y J. Arce (eds.), Estudios sobre la tabula Siariensis. Madrid, CSIC: 233-243.

Dopico Caínzos, M. D. (2017): «Los conventus iuridici: la aportación de la Naturalis Historia de Plinio el Viejo», P. Ciprés (ed.), Plinio el Viejo y la construcción de Hispania Citerior. Vitoria, Universidad del País Vasco: 243-272.

Durry, M. (1968): Les Cohortes Prétoriennes. París, Boccard.

Espinosa Ruiz, U. (1990): Vareia. Enclave romano en el Valle del Ebro. Logroño. 
Espinosa Ruiz, U. y Castillo Pascual, M. ${ }^{a}$ J. (1995-1997): «Novedades epigráficas en el medio Ebro (La Rioja)». Lucentum, 14-16: 101-112.

Faria, A. M. de (1999): «Colonizaçao e municipalizaçao nas provincias hispano-romanas: reanálise de alguns casos polémicos». Revista Portuguesa de Arqueologia, 2 (2): 29-50.

Forni, G. (1953): Il reclutamento delle legioni da Augusto a Diocleziano. Roma.

García-Gelabert Pérez, M. P. y Blázquez Martínez, J. M. (1987-1988): «Mercenarios hispanos en las fuentes literarias y en la arqueología». Habis, 18-19: 257-270.

García Martínez, M. ${ }^{a}$ R. (1991): «Caracteres y significación socio-económica de los movimientos de población hispana hacia las provincias imperiales en época romana». Hispania Antiqua, 15: 263302.

García Martínez, M. ${ }^{a}$ R. (1994a): «Desplazamientos de habitantes de la Bética hacia el Imperio en época romana», Actas del II Congreso de Historia de Andalucía. Córdoba, 1991. Córdoba, Universidad de Córdoba: 383-390.

García Martínez, M. ${ }^{a}$ R. (1994b): «Contribución de la provincia Lusitania al movimiento de población hispana hacia las provincias imperiales en época romana», S. Ordóñez Agulla y P. Sáez Fernández (coords.), Homenaje al profesor Presedo. Sevilla, Universidad de Sevilla: 457-462

Gimeno Pascual, H. (2004-2005): «Nuevos datos para la Colonia Salaria». Lucentum, 23-24: 181-184.

Gómez-Pantoja, J. (1999): «Historia de dos ciudades: Capera y Clunia», J. G. Gorges y F. Rodríguez Martín (eds.), Économie et territoire en Lusitanie romaine. Madrid, Casa de Velázquez: 91-108.

Gómez-Pantoja, J. L. y Castillo Sanz, F. J. (2014): «Una fórmula epigráfica fracasada: aera», F. Cadiou y M. Navarro Caballero (eds.), La guerre et ses traces. Bordeaux, Ausonius: 507-518.

González Rodríguez, M. ${ }^{a}$ C. (2017): «Grupos de población en la descripción de Plinio», P. Ciprés (ed.), Plinio el Viejo y la construcción de Hispania Citerior. Vitoria, Universidad del País Vasco: 127152.

Grüll, T. (2018): «Origo as identity factor in Roman epitaphs», G. Cupcea y R. Varga (eds.), Social Interactions and Status Markers in the Roman World. Oxford, Archaeopress Roman Archaeology: $139-150$.

Gutiérrez Merino, J. C. (2002): «La presencia de hispanos en la provincia romana de Britannia a través de las fuentes epigráficas», L. Hernández Guerra, L. Sagredo San Eustaquio, y J. M. Solana Sáinz (coords.), Actas del I Congreso Internacional de Historia Antigua. La Península Ibérica hace 2000 años. Valladolid, 23-25 de noviembre de 2000. Valladolid, Universidad de Valladolid: 229-234.

Haley, E. W. (1986): Foreigners in Roman Imperial Spain: investigations of geographical mobility in the spanish provinces of the Roman Empire (30 B.C. - A.D. 284). Columbia.

Haley, E. W. (1992): «Clunia, Galba and the Events of 68-69». ZPE, 91: 159-164.

Hernández Guerra, L. (1999): Epigrafia romana de unidades militares relacionadas con Petavonium (Rosino de Vidirales, Zamora). Estudio social, religioso y prosopográfico. Valladolid, Universidad de Valladolid.

Hernández Guerra, L. (2017): «Movilidad geográfica. Auxiliares y legionarios hispanos con mención de origo en el limes septentrional del Imperio», J. J. Ferrer Maestro, C. Kunst, D. Hernández de la Fuente y E. Faber (eds.), Entre los mundos: Homenaje a Pedro Barceló. Toulouse, 3 Presses universitaires de Franche-Comté: 379-416.

Kolendo, J. (2001): «Inscription d'un soldat originaire de Clunia découverte à Novae (Mésie Infériere)». Gerión, 19: 525-531.

Le Bohec Y. (1989): La Troisième Légion Auguste. París, Centre National de la Recherche Scientifique.

Le Bohec, Y. (ed). (2000): Les légions de Rome sous le Haut Empire. Lyon, De Boccard.

Le Bohec, Y. (2004): El ejército romano. Barcelona, Ariel.

Le Roux, P. (1982): L'armée romaine et l'organisation des provinces iberiques d'Auguste a l'invasion de 409. París, Boccard.

Magallón Botaya, M. ${ }^{a}$ A. y Navarro Caballero, M. (1991-1992): «Los desplazamientos humanos en el Conventus Caesaraugustanus según la epigrafía». Zephyrus, 44-45, 405-421.

Malone, S. (2005): Legio XX Valeria Victrix: a prosopographical and historical study. Nottingham, University of Nottingham.

Morales Rodríguez, E. M. ${ }^{\mathrm{a}}$ (2014): «Epigrafía legionaria en el Alto Guadalquivir», G. Bravo y R. González Salinero (eds.), Conquistadores y conquistados: relaciones de dominio en el mundo romano. Madrid-Salamanca, Signifer Libros: 217-232. 
Ortiz Córdoba, J. (2017): «Reclutamiento y unidades militares en las colonias de la Hispania Meridional». Florentia Iliberritana, 28: 135-158.

Ortiz Córdoba, J. (2018): «Reclutamiento y unidades militares en las colonias romanas de Lusitania». Studia Historica. Historia Antigua, 36: 83-116.

Ortiz Córdoba, J. (2019): Las colonias romanas de Hispania y los movimientos de población. Granada, Universidad de Granada. Tesis Doctoral.

Ozcáriz Gil, P. (2013). La administración de la Hispania citerior durante el Alto Imperio. Organización territorial, cargos administrativos y fiscalidad. Barcelona, Universidad de Barcelona.

Palao Vicente, J. J. (1998): «Sobre el envío de tropas de la Legio VII Gemina al limes africano». Studia Historica. Historia Antigua, 16: 149-172.

Palao Vicente, J. J. (2006): Legio VII Gemina (Pia) Felix. Estudio de una legión romana. Salamanca, Universidad de Salamanca.

Perea Yébenes, S. (1991): «Notas sobre la epigrafía militar en Clunia». Hispania Antiqua, 15: 193-206.

Perea Yébenes, S. (1994): «La Bética emisora y receptora de soldados legionarios durante el Alto Imperio romano», Actas del II Congreso de Historia de Andalucía. Córdoba, 1991. Córdoba, Universidad de Córdoba: 373-382.

Perea Yébenes, S. (2001): «Militares clunienses fuera de Hispania en los ejércitos de los Julio-Claudios y los Flavios», L. Hernández Guerra, L. Sagredo San Eustaquio, y J. M. Solana Sáinz (coords.), Actas del I Congreso Internacional de Historia Antigua. La Península Ibérica hace 2000 años. Valladolid, 23-25 de noviembre de 2000. Valladolid, Universidad de Valladolid: 213-219.

Perea Yébenes, S. (2002): «Epigrafía militar en publicaciones recientes (II)». Aquila Legionis, 2: 85106.

Perea Yébenes, S. (2004-2005): «Las «patrias» del soldado romano en el Alto Imperio». Espacio, Tiempo y Forma. Serie II, Historia Antigua, 17-18: 161-189.

Reddé, M. (1986): Mare Nostrum. Roma, École française de Rome.

Ricci, C. (1992): «Hispani a Roma». Gerión, 10: 103-143.

Ricci, C. (2005): «Ispanici a Roma nel II secolo. La componente militare», Actas del II Congreso Internacional de Historia Antigua: la Hispania de los Antoninos (98-180). Valladolid, Universidad de Valladolid: 267-276.

Rodríguez González, J. (2001): Historia de las legiones romanas. Madrid, Signifer-Libros.

Roldán Hervás, J. M. (1974): Hispania y el ejército romano. Salamanca, Universidad de Salamanca.

Weber, E. (2010): «Lavori di riedizione del CIL III (Pannonia): problemi i risultati», L. Zerbini (a cura di), Roma e le province del Danubio. Atti del I Convegno Internazionale Ferrara-Cento. 15-17 Ottobre 2009, Ferrara, Rubbettino: 197-207.

Wiegels, R. (1985): Die Tribusinschriften des romischen Hispanien, Berlín, De Gruyter.

Zaharide, M. (2007): «Alae Thracum», M. Mayer Olivé, G. Baratta y A. Guzmán Almagro (eds.), XII Congressus Internationalis Epigraphiae-Graecae et Latinae. Barcelona, Institut d'Estudis Catalans: $1497-1512$.

Recibido: 14-02-2019

Aceptado: 25-04-2019 